\title{
A long-term survivor keeping in a complete response without treatment after pemetrexed maintenance therapy for advanced non-squamous non-small cell lung cancer
}

\author{
Makoto Furugen $^{1}$, Daisuke Shibahara ${ }^{1}$, Tomo Kiyuna ${ }^{1}$, Wakaki Kami ${ }^{1}$, Kazuya Miyagi ${ }^{1}$, \\ Shusaku Haranaga ${ }^{1}$, Toru Kubota ${ }^{2}$, Hirofumi Matsumoto ${ }^{3}$, Naoki Yoshimi ${ }^{4}$, and Jiro \\ Fujita $^{1}$ \\ ${ }^{1}$ University of the Ryukyus Faculty of Medicine Graduate School of Medicine \\ ${ }^{2}$ Affiliation not available \\ ${ }^{3}$ Nakagami Hospital \\ ${ }^{4}$ Okinawa Red Cross Hospital
}

September 11, 2020

\begin{abstract}
Molecular targeted drugs and immune checkpoint blockades are not indicated for all advanced non-small cell lung cancer (NSCLC) cases. For such patients, cytotoxic drugs are the main treatment, and the prognosis remains poor. We present a valuable case of advanced NSCLC that was potentially permanent cured by pemetrexed maintenance chemotherapy.
\end{abstract}

\section{Key Clinical Message}

Pemetrexed has significant efficacy for some non-squamous non-small cell lung cancer cases, as demonstrated in the current case. For those patients, pemetrexed administration should be carefully considered.

\section{Introduction}

Molecular targeted drugs and immune checkpoint blockades have remarkably improved outcomes for patients with advanced non-small cell lung cancer (NSCLC) $(1,2)$. However, those drugs are not indicated for all advanced NSCLC cases. For such patients, cytotoxic drugs are the main treatment, and the prognosis remains poor.

Here, we report a patient with advanced non-squamous (non-Sq) NSCLC and malignant pleural effusion who was treated with cytotoxic drugs: cisplatin-based induction chemotherapy, followed by pemetrexed maintenance therapy (PMT), to which she achieved a durable complete response (CR) for six years to date, after discontinuing all drug treatments.

\section{Clinical Case}

A 46-year-old Japanese woman with a 12-pack/year smoking history with no asbestos exposure, presented with a chronic dry cough at a neighborhood hospital. Her chest images showed diffuse thickening of the right pleura with pleural effusion (Fig. 1A-C). After excluding infectious diseases, she was suspected to have a malignant disease, because of the positive cytology of her right pleural effusion. A percutaneous right-pleural biopsy examination revealed stage IV (T4N2M1a) non-Sq NSCLC (Fig. 2A, B) with immunostaining was positive for Ber-EP4 (Fig. 2C) and slightly positive for CEA (data not shown) as carcinoma markers, and negative immunostaining for calretinin (Fig. 2D) and D2-40 (data not shown) as mesothelioma markers. 
In that hospital, she was first treated with gefitinib, an epidermal growth factor receptor (EGFR) tyrosine kinase inhibitor, as non-Sq NSCLC in a young Japanese woman might reasonably be expected to have an EGFR mutation. However, her tumor did not improve, and was subsequently found to have no EGFR mutation. Gefitinib treatment was stopped after four weeks.

For her second-line treatment, she was referred to our hospital. On admission, drainage to her right pleural space was not feasible, as the prolonged pleural effusion had produced a sclerosing tumor. As systemic chemotherapy, cisplatin $\left(75 \mathrm{mg} / \mathrm{m}^{2}\right)$ and pemetrexed $\left(500 \mathrm{mg} / \mathrm{m}^{2}\right)$ were started, which led to a good partial response after the second cycle, as shown by computed tomography (Fig. 3A,B). Bevacizumab was suggested but not added to this regimen, due to patient's refusal in consideration for its adverse effects (AEs). She received PMT (500 mg $/ \mathrm{m}^{2}$, every 21 or 28 days) followed by four cycles of the induction regimen of cisplatin and pemetrexed, and her pleural lesion continued to diminished, resulting in a CR at the $29^{\text {th }}$ PMT cycle (Fig. 3C, D). Her serum carcinoembryonic antigen (CEA) had been elevated (198 $\mathrm{ng} / \mathrm{mL}$ at its zenith) during her second-line treatment, but had normalized with the success of PMT. She had not suffered any severe AE that would have required stopping chemotherapy, but did experience grade 2 hepatic dysfunction and grade 1 edema.

Although PMT was stopped at the $32^{\text {th }}$ cycle at her insistence, she has retained a durable CR without recurrence for 73 months to date (Fig. 4A-D). She has survived for eight-and-a-half years from the diagnosis of advanced non-Sq NSCLC, and has remained disease-free without drug therapy for six years.

\section{Discussion}

This case required a differential diagnosis between primary lung cancer and malignant pleural mesothelioma, because of the diffuse right-side pleural thickening and effusion shown on her chest images. Immunostaining for at least 2 carcinoma markers (Ber-EP4: positive; CEA: slightly positive) and 2 mesothelial markers (calretinin and D2-40: both negative) was useful for this patient's diagnosis (3). Elevated serum CEA (a negative tumor marker for mesothelioma) also helped rule out malignant pleural mesothelioma. She was diagnosed as non-Sq NSCLC for having no cytological cornification, in a difficult condition of determining exact histological type with artifact.

Administering PMT after an induction combination of cisplatin and pemetrexed reportedly has a survival benefit for patients with advanced non-Sq NSCLC (4), and so PMT has become a standard chemotherapy for those patients. In the above-mentioned phase III trial, the median number of maintenance cycles in the PMT arm was $7.9 ; 28 \%$ in the PMT arm received $>10$ cycles of maintenance therapy, $10 \%$ received $>20$ cycles, and $4 \%$ received $>30$ cycles. Median overall survival (from the start of maintenance treatment) in the PMT arm was 13.9 months $(4,5)$. In the present case, the patient could have received the 32 cycles of PMT after the induction chemotherapy of cisplatin and pemetrexed for four cycles. She had mild AEs-grade 2 hepatic dysfunction and grade 1 edema-which were in line with previous reports of PMT $(4,5)$. Considering the absence of severe AEs, the high effectiveness of PMT, and her strong motivation for the therapy, she could have received PMT for a longer period.

As pemetrexed has been shown to be effective against non-Sq NSCLC $(6,7)$ and malignant pleural mesothelioma (8), and is therefore often used to treat these diseases. CR outcomes have been attributed to pemetrexed in some reports of non-Sq NSCLC and malignant pleural mesothelioma $(9,10)$. In this case, the patient reached in a CR, with the disappearance of pleural malignancy, by PMT use, in addition to keeping a longer $\mathrm{CR}$ than in previous reports-73 months after discontinuing PMT. This case implies the possibility of a permanent cure of non-Sq NSCLC through the cytotoxic chemotherapy; PMT.

Pemetrexed is a multitargeted antifolate that inhibits multiple enzymes, such as thymidylate synthase (TS) and dihydrofolate reductase (DHFR). TS and DHFR expressions negatively correlate with the treatment efficacy of pemetrexed in NSCLC patients; non-Sq NSCLC patients with low TS and DHFR expression levels tend to have high responsiveness $(10,11,12)$. In addition, up-regulated $T S$ gene expression has a function in acquired pemetrexed resistance in NSCLC $(10,13)$. In contrast, NSCLC that harbors translocation of the anaplastic lymphoma kinase $(A L K)$ gene has been shown to be highly responsive to pemetrexed (14), which 
suggests that this patient's tumor is likely to have a $A L K$ translocation, although the lack of an appropriate specimen precludes testing for $A L K$ translocation. If the patient ever has a disease recurrence, she might undergo re-biopsy to ascertain $A L K$ translocation, and TS and DHFR expression.

\section{Conclusion}

We present a valuable case of advanced non-Sq NSCLC, treated with pemetrexed which led to a CR and longterm survival without recurrence for six years so far, after discontinuing all the drug treatments. Pemetrexed has significant efficacy for some non-Sq NSCLC cases, as demonstrated in the current case. For the patients with advanced non-Sq NSCLC, pemetrexed administration should be carefully considered.

\section{Funding}

This research did not receive any specific grant from funding agencies in the public, commercial, or not-forprofit sectors.

\section{Conflict of interest}

The authors have no conflicts of interest.

\section{Declarations of interest}

None.

\section{Acknowledgment}

We thank Marla Brunker, from Edanz Group (www.edanzediting.com/ac), for editing a draft of this manuscript.

\section{Author Contributions}

MF: Primary author and Correspondence author;

DS: Manuscript analysis; TK: Manuscript analysis; WK: Manuscript analysis;

KM: Manuscript analysis; SH: Manuscript analysis; TK: Manuscript analysis;

HM: Pathological analysis; NY: Pathological analysis;

JF: Manuscript analysis.

\section{References}

1. Okamoto I, Morita S, Tashiro N, Imamura F, Inoue A, Seto T, Yamamoto N, Ohe Y, Nakagawa K, Fukuoka M. Real world treatment and outcomes in EGFR mutation-positive non-small cell lung cancer: Long-term follow-up of a large patient cohort. Lung Cancer . 2018;117:14-19.

2. Reck M, Rodríguez-Abreu D, Robinson AG, Hui R, Csőszi T, Fülöp A, Gottfried M, Peled N, Tafreshi A, Cuffe S, O'Brien M, Rao S, Hotta K, Leiby MA, Lubiniecki GM, Shentu Y, Rangwala R, Brahmer JR; KEYNOTE-024 Investigators. Pembrolizumab versus Chemotherapy for PD-L1-Positive Non-SmallCell Lung Cancer. N Engl J Med . 2016;375(19):1823-1833.

3. Husain AN, Colby TV, Ordóñez NG, Allen TC, Attanoos RL, Beasley MB, Butnor KJ, Chirieac LR, Churg AM, Dacic S, Galateau-Sallé F, Gibbs A, Gown AM, Krausz T, Litzky LA, Marchevsky A, Nicholson AG, Roggli VL, Sharma AK, Travis WD, Walts AE, Wick MR, Guidelines for Pathologic Diagnosis of Malignant Mesothelioma 2017 Update of the Consensus Statement From the International Mesothelioma Interest Group.Arch Pathol Lab Med . 2018;142(1):89-108.

4. Paz-Ares LG, de Marinis F, Dediu M, Thomas M, Pujol JL, Bidoli P, Molinier O, Sahoo TP, Laack E, Reck M, Corral J, Melemed S, John W, Chouaki N, Zimmermann AH, Visseren-Grul C, Gridelli C. PARAMOUNT: Final overall survival results of the phaseIII study of maintenance pemetrexed versus placebo immediately after induction treatment with pemetrexed plus cisplatin for advanced nonsquamous non-small-cell lung cancer. J Clin Oncol . 2013;31(23):2895-2902. 
5. Pujol JL, Paz-Ares L, de Marinis F, Dediu M, Thomas M, Bidoli P, Corral J, San Antonio B, Chouaki N, John W, Zimmermann A, Visseren-Grul C, Gridelli C. Long-term and low-grade safety results of a phase III study (PARAMOUNT): maintenance pemetrexed plus best supportive care versus placebo plus best supportive care immediately after induction treatment with pemetrexed plus cisplatin for advanced nonsquamous non-small-cell lung cancer. Clin Lung Cancer . 2014;15(6):418-425.

6. Scagliotti GV, Parikh P, von Pawel J, Biesma B, Vansteenkiste J, Manegold C, Serwatowski P, Gatzemeier U, Digumarti R, Zukin M, Lee JS, Mellemgaard A, Park K, Patil S, Rolski J, Goksel T, de Marinis F, Simms L, Sugarman KP, Gandara D. Phase III study comparing cisplatin plus gemcitabine with cisplatin plus pemetrexed in chemotherapy-naive patients with advanced-stage non-small-cell lung cancer. J Clin Oncol . 2008;26(21):3543-3551.

7. Scagliotti G, Hanna N, Fossella F, Sugarman K, Blatter J, Peterson P, Simms L, Shepherd FA. The differential efficacy of pemetrexed according to NSCLC histology: a review of two Phase III studies. Oncologist . 2009;14(3):253-263.

8. Vogelzang NJ, Rusthoven JJ, Symanowski J, Denham C, Kaukel E, Ruffie P, Gatzemeier U, Boyer M, Emri S, Manegold C, Niyikiza C, Paoletti P. Phase III study of pemetrexed in combination with cisplatin versus cisplatin alone in patients with malignant pleural mesothelioma.J Clin Oncol . 2003;21(14):2636-2644.

9. Tada A, Sakaguchi K, Kobayashi M, Kagoshima T, Yamazaki Y, Kamisawa O. A case of adenocarcinoma of the lung with malignant pleural effusion in elderly patient treated effectively by pemetrexed and carboplatin. (in Japanese.). Gan To Kagaku Ryoho . 2012;39(3):425-427.

10. Takeda T, Itano H, Fukita S, Saitoh M, Takeda S. Long progression-free survival by pemetrexed continuation maintenance therapy following cisplatin-based chemotherapy in malignant pleural mesothelioma.Intern. Med . 2014;53(20):2347-2351.

11. Chen CY, Chang YL, Shih JY, Lin JW, Chen KY, Yang CH, Yu CJ, Yang PC. Thymidylate synthase and dihydrofolate reductase expression in non-small cell lung carcinoma: the association with treatment efficacy of pemetrexed. Lung Cancer . 2011;74(1):132-138.

12. Sun JM, Han J, Ahn JS, Park K, Ahn MJ. Significance of thymidylate synthase and thyroid transcription factor 1 expression in patients with nonsquamous non-small cell lung cancer treated with pemetrexed-based chemotherapy. $J$ Thorac Oncol . 2011;6(8):1392-1399.

13. Ozasa H, Oguri T, Uemura T, Miyazaki M, Maeno K, Sato S, Ueda R. Significance of thymidylate synthase for resistance to pemetrexed in lung cancer. Cancer Sci . 2010;101(1):161-166.

14. Shaw AT, Kim DW, Nakagawa K, Seto T, Crino L, Ahn MJ, De Pas T, Besse B, Solomon BJ, Blackhall F, Wu YL, Thomas M, O’Byrne KJ, Moro-Sibilot D, Camidge DR, Mok T, Hirsh V, Riely GJ, Iyer S, Tassell V, Polli A, Wilner KD, Janne PA. Crizotinib versus chemotherapy in advanced ALK-positive lung cancer. N Engl J Med . 2013;368(25):2385-2394.

\section{Figure legends}

Figure 1. Radiological findings at admission to our hospital. Chest X-ray showed decreased radiolucency in the right upper-peripheral, middle and lower lung fields with dullness at the right costophrenic angle (A). Chest computed tomography shows diffuse thickening of the right pleura with effusion (B, C).

Figure 2. Percutaneous pleural biopsy specimen shows (A, B) no cornification in non-Sq NSCLC; (C), positive staining for Ber-EP4 (carcinoma marker); (D) negative staining for calretinin (mesothelioma marker). (A: hematoxylin/eosin staining, 4x original magnification; B-D: 20x original magnification.)

Figure 3. Chest computed tomography shows improved pleural disease after cytotoxic chemotherapy (A, B: after two cycles of cisplatin and pemetrexed) (C, D: after 29 cycles of maintenance pemetrexed, leading to a complete response).

Figure 4. Proton emission tomography, two months after discontinuing maintenance pemetrexed, shows no enhanced signal throughout the body (A). Chest X-ray after 51 months (B) and chest computed tomography at 54 months after discontinuing PMT show no recurrence (C, D). 


\section{Hosted file}

PEM-CR. Clinical Case Reports (Fig. 1) (Makoto Furugen).ppt available at https://authorea. com/users/356112/articles/479096-a-long-term-survivor-keeping-in-a-complete-responsewithout-treatment-after-pemetrexed-maintenance-therapy-for-advanced-non-squamous-nonsmall-cell-lung-cancer

\section{Hosted file}

PEM-CR. Clinical Case Reports (Fig. 2) (Makoto Furugen).ppt available at https://authorea. com/users/356112/articles/479096-a-long-term-survivor-keeping-in-a-complete-responsewithout-treatment-after-pemetrexed-maintenance-therapy-for-advanced-non-squamous-nonsmall-cell-lung-cancer

\section{Hosted file}

PEM-CR. Clinical Case Reports (Fig. 3) (Makoto Furugen).ppt available at https://authorea. com/users/356112/articles/479096-a-long-term-survivor-keeping-in-a-complete-responsewithout-treatment-after-pemetrexed-maintenance-therapy-for-advanced-non-squamous-nonsmall-cell-lung-cancer

\section{Hosted file}

PEM-CR. Clinical Case Reports (Fig. 4) (Makoto Furugen).ppt available at https://authorea. com/users/356112/articles/479096-a-long-term-survivor-keeping-in-a-complete-responsewithout-treatment-after-pemetrexed-maintenance-therapy-for-advanced-non-squamous-nonsmall-cell-lung-cancer 